\section{Enhancement of immunohisto- chemical detection of Salmonella in tissues of experimentally infected pigs}

\author{
J. Rieger, ${ }^{1}$ P. Janczyk, ${ }^{2}$ H. Hünigen, \\ J. Plendl ${ }^{1}$ \\ 'Department of Veterinary Medicine, \\ Institute of Veterinary Anatomy, Freie \\ Universität Berlin \\ 2Department of Biological Safety, Unit \\ Molecular Diagnostics and Genetics, \\ Federal Institute for Risk Assessment, \\ Berlin, Germany
}

\section{Abstract}

Salmonella Typhimurium is one of the main pathogens compromising porcine and human health as well as food safety, because it is a prevailing source of foodborne infections due to contaminated pork. A prominent problem in the management of this bacteriosis is the number of subclinically infected carrier pigs. As very little is known concerning the mechanisms allowing Salmonella to persist in pigs, the objective of this study was to develop an immunohistochemical approach for the detection of salmonellae in tissue of pigs experimentally infected with Salmonella Typhimurium. Samples were obtained from a challenge trial in which piglets of the German Landrace were intragastrically infected with Salmonella enterica serovar Typhimurium DT104 (1.4-2.1×1010 CFU). Piglets were sacrificed on days 2 and 28 post infection. Tissue samples of jejunum, ileum, colon, ileocecal mesenteric lymph nodes (Lnn. ileocolici), and tonsils (Tonsilla veli palatini) were fixed in Zamboni's fixative and paraffin-embedded. Different immunohistochemical staining protocols were evaluated. Salmonella was detected in varying amounts in the tissues. Brown iron-containing pigments in the lymph nodes interfered with the identification of Salmonella if DAB was used as a staining reagent. Detergents like Triton X-100 or Saponin enhanced the sensitivity. It seems advisable not to use a detection system with brown staining for bacteria in an experimental setup involving intestinal damage including haemorrhage. The use of detergents appears to result in a higher sensitivity in the immunohistochemical detection of salmonellae.

\section{Introduction}

Salmonella is an important pathogen threatening porcine and human health as well as food safety. Amid the most pervasive sources of foodborne diseases, Salmonella enterica serovar Typhimurium ( $S$. Typhimurium) is especially strongly linked with human disease caused by the consumption of contaminated pork..$^{1-3}$ In pigs, an $S$. Typhimurium infection triggers clinical symptoms with enterocolitis, often followed or accompanied by sub-clinical infections of silent carrier animals that can function as a reservoir, infect other animals and transmit the pathogen to the food chain. ${ }^{4-6}$ Salmonella infects cells lining the epithelial layer of the small and large intestine such as M-cells, absorptive enterocytes or goblet cells and may cross this barrier via different mechanisms to invade the lamina propria.$^{7-9}$ After reaching the lamina propria of the intestinal mucosa, Salmonella is mainly taken up by macrophages in which they then replicate in a protected intracellular niche and which may also transmit the bacteria to other organs. ${ }^{10,11}$ Salmonellae harbour a sophisticated arsenal of mechanisms to survive and replicate in the host. Although bacterial persistence is a key phase of a pathogen's life cycle and represents an opportunity for disease control, very little is known about how the pathogen survives for long periods of time in the mammalian host in the presence of immunosurveillance. ${ }^{12}$ In order to study the largely unknown mechanisms used by Salmonella to persist in pigs ${ }^{5}$ and particularly to trace Salmonella's route through the body, it is a great challenge to reliably mark and track salmonellae in histological sections of different organs and tissues. As part of a big research consortium, one aim of our working group was the demonstration of $S$. Typhimurium in paraffin embedded tissues from experimentally infected pigs. Since immunohistochemistry represents a suitable approach to do this, ${ }^{13}$ we evaluated several protocols for applicability which yielded very heterogeneous results. The refined immunohistochemical protocol is presented. Further information concerning other aspects of the same experiment may be found elsewhere. ${ }^{14,15}$

\section{Materials and Methods}

\section{Sample collection}

The samples for this study were obtained during a Salmonella challenge trial already described. ${ }^{14}$ In short, samples were obtained from a probiotic feeding trial in which piglets of the German Landrace were intragastrically challenged with Salmonella enterica serovar

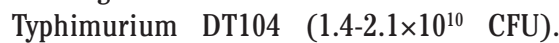
Piglets from each group were sacrificed on days 2 and 28 post infection (DPI). The animals were euthanized by an overdose of pentobarbiturates (Narcoren, Merial $\mathrm{GmbH}$,
Correspondence: Juliane Rieger, Department of Veterinary Medicine, Institute of Veterinary Anatomy, Freie Universität Berlin, Koserstraße 20, 14195 Berlin, Germany.

Tel. +49.30 .83853483 - Fax: +49.30 .83853480 .

E-mail: Juliane.Rieger@fu-berlin.de

Key words: Swine; immunohistochemistry; histochemistry; bacteria; detection limit.

Contributions: JR, study conception and design, critical literature review, data acquisition, analysis and interpretation, manuscript drafting and final approval; PJ, study conception and design, data acquisition; manuscript drafting and final approval; HH, study conception and design, data analysis and interpretation, critical review, final approval; JP, study conception and design, data analysis and interpretation, manuscript drafting and final approval.

Conflict of interest: the authors declare that there is no conflict of interest that could be perceived as prejudicing the impartiality of the research reported.

Acknowledgments: this study was supported by the German Research Foundation (DFG) through the Collaborative Research Centre 852 (Grant no. SFB852/1, www.sfb852.de). The authors wish to acknowledge the role in collection and preparation of samples, particularly the excellent technical assistance and expertise, of Karin BriestForch, Barbara Drewes, Tania Fuhrmann-Selter, Verena Holle, Monika Sachtleben and Ilka Slosarek, and Wiebke Gentner for her help with the proofreading; all are from the Institute of Veterinary Anatomy, Freie Universität Berlin.

Received for publication: 10 March 2015. Accepted for publication: 15 May 2015.

This work is licensed under a Creative Commons Attribution NonCommercial 3.0 License (CC BYNC 3.0).

\section{(C) Copyright J. Rieger et al., 2015}

Licensee PAGEPress, Italy

European Journal of Histochemistry 2015; 59:2516 doi:10.4081/ejh.2015.2516

Germany) under general azaperone (Stresnil, Janssen Animal Health, Neuss, Germany) -ketamine (10\% ketamine, Bremer Pharma $\mathrm{GmbH}$, Warburg, Germany) anaesthesia. Samples of mid-jejunum, ileum, colon ascendens, ileocecal mesenteric lymph nodes (Lnn. ileocolici), and tonsils (Tonsilla veli palatini) were taken within 15 min after sacrifice and treated as already described. ${ }^{14,16}$ All samples were rinsed in ice-cooled Ringer solution. Intestinal samples were cut open on the mesenterial side, trimmed to squares and pinned on cork pieces with the mucosal side facing upwards. The tissues were fixed for $26 \mathrm{~h}$ in Zamboni's fixation solution and rinsed in PBS, dehydrated in a 
graded series of ethanol, embedded in paraffin, cut to $5 \mu \mathrm{m}$ thin sections, mounted on HistoBond ${ }^{\circledR}$ slides (Paul Marienfeld $\mathrm{GmbH} \&$ Co. KG, Lauda-Königshofen, Germany), dewaxed in xylene and rehydrated in a decreasing series of ethanol. Experimental approval had been given by the local authority / Regional Office for Health and Social Affairs Berlin (Landesamt für Gesundheit und Soziales, Berlin ID: G0348/09).

\section{Immunohistochemistry}

Different immunohistochemical staining protocols with a monoclonal mouse antiSalmonella Typhimurium antibody (Mouseanti-Salmonella Typhimurium, monoclonal, Maus-IgG, 5mg/mL, Clone $8 \mathrm{C} 11 \mathrm{C}$, Acris Antibodies $\mathrm{GmbH}$, Herford, Germany) were evaluated. Two protocols are presented here for comparison (Table 1).

\section{Pigment differentiation / iron demonstration}

For the identification of the gold-brown pigments encountered in lymph nodes, the very same histological samples employed for immunohistochemistry were used. For the demonstration of iron, Berlin blue method (trivalent iron) and Turnbull blue method mod- ified according to Quincke (bi- and trivalent iron) were applied. ${ }^{17}$ Lipofuscin was detected according to Hueck and Pearse. ${ }^{18}$ To validate the staining protocols, liver samples of goat, sheep, cow or rat, available in our institute from stock, were used as positive controls. The liver was chosen, since a number of different pigments may be seen as an incidental finding within hepatocytes and Kupffer cells, amongst them lipofuscin and hemosiderin. ${ }^{19}$

\section{Results}

\section{Immunohistochemical detection of Salmonella}

$S$. Typhimurium was detected immunohistochemically in varying amounts depending on the time post-infection, tissue localization and the protocol used. The positively stained objects appeared as roundish to longish particles with a diameter of $\sim 2 \mu \mathrm{m}$. With protocol 1 , single bacteria were observed lying freely between cells of tissues as well as intracellularly, often in cells with the morphology of macrophages (Figure 1). Salmonellae were abundant in the tunica mucosa of ileum and colon 2 DPI, where several bacteria appeared to group in clusters. The ileal domes were particularly frequented by the pathogen. $S$. Typhimurium was found in lymph nodes, albeit in low numbers, and was not detectable in tonsils. In addition to the immunohistochemically labelled salmonellae, spots of brown pigment with the same size as the bacteria were visible in sections of lymph nodes. They also appeared in the control sections (Figure 2C). As the brown iron-containing pigments (see below) in the lymph nodes interfered with the identification of Salmonella if DAB was used as a staining reagent, HistoGreen was used instead, which labels the targeted bacteria in a bright green-blue color (Figure 2 D,E). After implementing a permeabilization step with detergents like Triton X-100 or Saponin (protocol 2), we found that the sensitivity was considerably enhanced. More staining signals were visible and we also found the bright green-blue color easier to recognize (Figure 3 ). In addition to a higher amount of Salmonella, which could now be detected in ileal and colonic tissues, it was now frequently possible to show the presence of bacteria in lymph nodes and tonsils. In lymph nodes and tonsils the staining signals were dispersed throughout the tissue and the bacteria appeared not to be grouped in clusters (Figure 3D). In the positive controls derived from cul-

Table 1. Comparison of immunohistochemical protocols. If not stated otherwise, all steps were carried out at room temperature. All incubation steps were carried out in a humid chamber. As additional positive control, cultured bacteria were used; therefore Salmonella containing culture medium was dropped on slides and heat fixed. The slides where treated in the same way as the tissue sections.

Protocol 1 Protocol 2

Rinsing of the rehydrated sections in $0.01 \mathrm{M}$ citrate buffer, $\mathrm{pH} 6.0$

Heat induced epitope retrieval: $0.01 \mathrm{M}$ citrate buffer, $\mathrm{pH} 6.0,96^{\circ} \mathrm{C}, 25 \mathrm{~min}$

Cooling down of the section container 15 min at room temperature and 5 min in cold tap water

Rinsing of the sections in Aq. Bidest 2 min

Surrounding of sections with a hydrophobic barrier using a barrier pen (S2002, Dako Deutschland GmbH, Hamburg, Germany)

Rinsing of the sections in TBS $(0.05 \mathrm{M}$ Tris-HCl pH $7.6+0.9 \% \mathrm{NaCl}) 2 \times 3 \mathrm{~min}$

Peroxidase-block: $3 \% \mathrm{H}_{2} \mathrm{O}_{2}$ in TBS 20 min

Rinsing in TBS 5 min

Rinsing in TBS $+0.05 \%$ Tween $20^{\circledR} 5 \mathrm{~min}$

Rinsing in PBS + 0.1\% saponin or PBS + 0.1\% Triton X-100 20 min

Preincubation: $3 \% \mathrm{BSA}+5 \%$ normal goat serum in TBS 30 Preincubation: $3 \%$ BSA in PBS 20

Primary antibody incubation: 1:2500 in TBS + 1\% BSA + 2\% normal goat serum Isotype control (mouse IgG1, DAKO X0931, $100 \mu \mathrm{g} / \mathrm{mL}$, Dako Deutschland GmbH, Primary antibody incubation: 1:5000 in PBS + 1\% BSA Isotype control (mouse IgG1, DAKO X0931, $100 \mu \mathrm{g} / \mathrm{mL}$, Hamburg, Germany): 1:50 in TBS + 1\% BSA + 2\% normal goat serum Buffer control: TBS $+1 \%$ BSA $+2 \%$ normal goat serum; overnight at $4^{\circ} \mathrm{C}$ Dako Deutschland GmbH, Hamburg, Germany): 1:500 in PBS + 1\% BSA Rinsing in TBS $1 x$ 3' Buffer control: $1 \%$ BSA in PBS; overnight at $4^{\circ} \mathrm{C}$

DAKO EnVision+-System/HRP labelled goat-anti-mouse-polymer (DAKO K4001, Dako Deutschland GmbH, Hamburg, Germany) was applied for 40 min in the dark. Rinsing in TBS $1 x 5$ min and PBS 1x 5 min Rinsing in PBS 2x 5

HRP detection: DAB 30 min in the dark or HistoGreen HRP detection: HistoGreen (Linaris, Wertheim-Bettingen, Germany) 10 min

(Linaris, Wertheim-Bettingen, Germany) $10 \mathrm{~min}$

Rinsing in PBS 2x 3 min; rinsing in Aq. Dest

Counterstaining: Haemalaun AD Mayer for $\sim 12 \mathrm{sec}$ in Aq. Bidest, 2 min bluing in tap water

Dewater: 100\% ethanol 3x $60 \mathrm{sec}$, Xylene 2x 1 min

Addition of mounting medium and coverslip 
tured $S$. Typhimurium, the staining intensity between single bacteria varied notably. Whereas approximately $1 \%$ of the bacteria exhibited a strong positive reaction and circa $5-10 \%$ exhibited a moderate staining signal, most cells showed very weak or almost invisible staining grades. The strongly stained bacteria were the biggest ones. They were rodshaped and the staining signal was situated at the perimeter of the cells. The moderately stained cells appeared to be a little smaller and were also rod shaped. Bacteria with weak or nearly no staining appeared to be the smallest ones and exhibited a more roundish shape. A similar phenomenon could be observed in the tissue samples, in which the staining intensity differed between single bacteria in the gut lumen and inside the tissue (Figure 3C).

\section{Pigment differentiation / iron demonstration}

In the above mentioned samples of lymph nodes, particularly in their medulla, spots of brown pigment were visible, which had the same size as the expected immunohistochemical reaction product for $S$. Typhimurium (Figure $2 \mathrm{~A}, \mathrm{C}$ ). Iron deposits were positively demonstrated using Turnbull blue and Berlin blue (Figure 2B). Lipofuscin reaction was negative. Positive staining reactions for lipofuscin as well as iron were detectable in the positive controls.

\section{Discussion}

Histochemistry, especially immunohistochemistry, is a suitable approach to investigate the exact localization of a pathogen in situ. It enables the researcher to correlate its occurrence to e.g. pathologic lesions or other pathogens. $^{20,21}$ In the present study, $S$. Typhimurium was detected immunohistochemically in different porcine tissues of the intestine and in the tonsils. Frequently, the pathogen was spotted within cells, often in those which morphologically resembled macrophages. The staining results concerning bacterial morphology and distribution were principally comparable to descriptions found in the literature..$^{6,822-24}$ In the sections of lymph nodes including control sections (IgG - and buffer control), spots of brown pigment of approximately the same size as the expected immunohistochemical reaction product for $S$.
Typhimurium were visible. Since these pigment granules were of similar size and color as the labelled bacteria, it was necessary to distinguish them from the microorganisms. The pigment granules were found to contain iron, presumably representing hemosiderin, which can be a result of mucosal haemorrhages. ${ }^{25,26}$ Consequently, the detection system was changed to a green color to solve this problem, although it has to be noted that DAB gives a more crisp staining result compared to HistoGreen. It seems advisable not to use a detection system with brown staining in experimental setups involving intestinal damage including haemorrhage.

Immunohistochemistry is a powerful tool to demonstrate microorganisms in tissue samples; ${ }^{27}$ however, an important question can be raised concerning its detection limit. As microorganisms are at the limit of light microscopical detection and results may vary from slide to slide because of heterogeneous distribution of the bacteria in the tissue, histology is not the method of choice for routine diagnosis and quantification of bacterial infections in tissues..$^{22}$ One method routinely used to detect and quantify microbes is microbial plate counting. Interestingly, an organ-specific difference

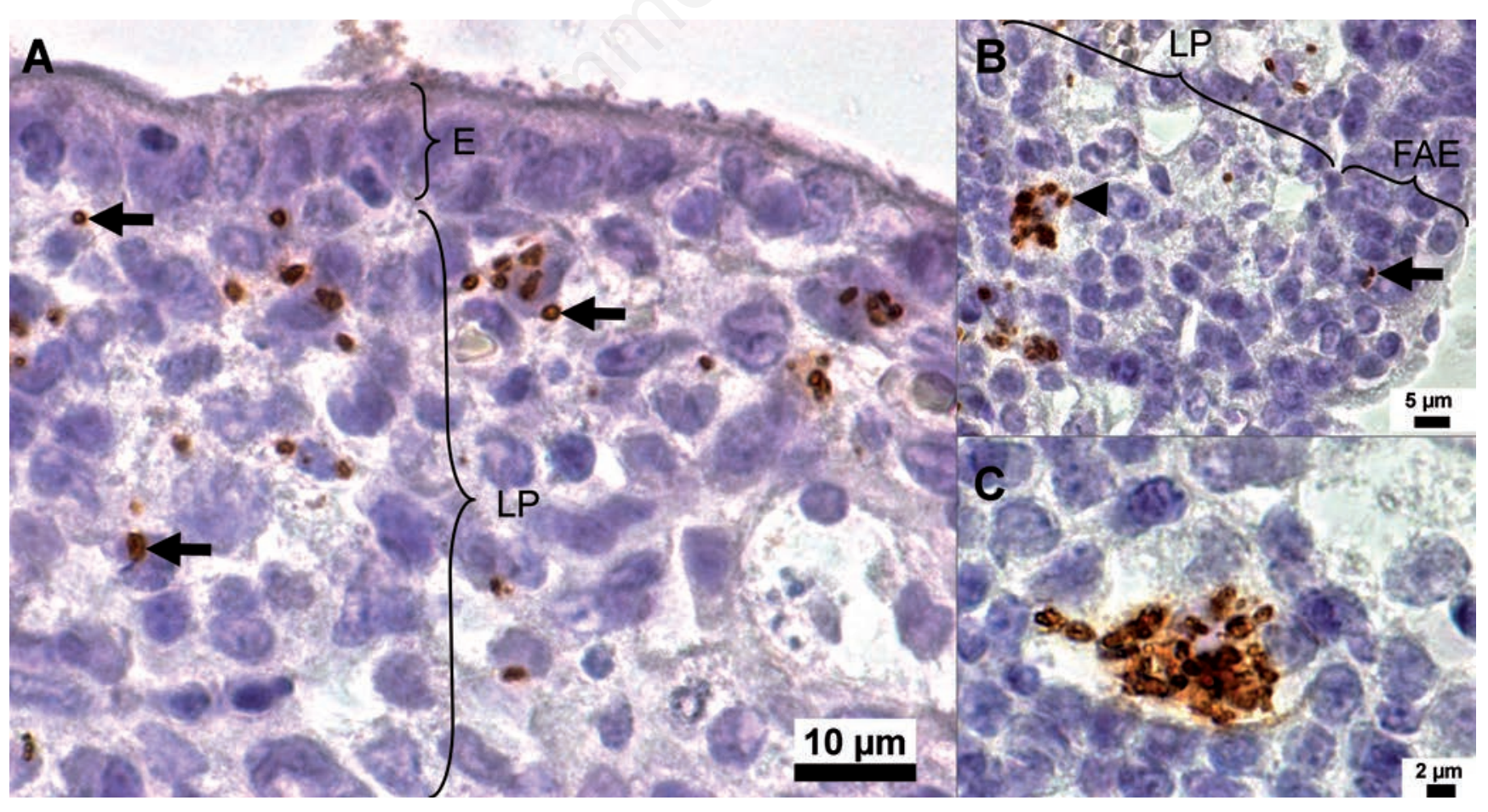

Figure 1. Immunohistochemistry. A) Salmonella (arrows) can be seen as ca. $2 \mu \mathrm{m}$ big objects outlined in brown staining with DAB in the ileal mucosa directly under the epithelium (E) in the lamina propria (LP). B) Ileal dome, with follicle associated epithelium (FAE). Bacteria are situated within the FAE (arrow) and in the underlying lamina propria (LP) (arrowhead). C) A Salmonella containing cell, morphologically resembling a macrophage, in the lamina propria of the ileum is illustrated. 
between results of our immunohistochemical labelling of $S$. Typhimurium and microbial plate counting done in the same trial by Kreuzer et al. could be found. ${ }^{2} 2$ DPI levels around $10^{3} \mathrm{CFU} / \mathrm{g}$ tissue could be quantified via plate counting in the tonsils, jejunum and lymph nodes, whereas $S$. Typhimurium was hardly detectable in these organs via immunohistochemistry using protocol 1 . In contrast, immunohistochemistry of $S$. Typhimurium in ileal and colonic tissue 2 DPI was reliably possible. Plate counting done for these organs resulted in higher levels, namely between $10^{4}$ $10^{6} \mathrm{CFU} / \mathrm{g}$ tissue. We therefore conclude that the number of CFUs was under the immunohistochemical detection limit in tonsils, jejunum and lymph nodes with protocol 1. In protocol 1 we applied only a low concentration $(0.05 \%)$ of a mild membrane solubiliser (Tween 20) for a short time (5 min). In protocol 2 we applied a higher concentration (0.1\%) of a mild detergent (Saponin) or a harsh detergent (Triton X-100) for a longer time (20 min). This modification enhanced the immunohistochemical sensitivity enormously and $S$. Typhimurium was also detectable in the previously negative organs. The observation of sensitivity enhancement due to detergents stands in contrast to the statement that antigen retrieval is in general not required for the demonstration of bacteria in fixed tissues. ${ }^{28}$ For example Searle, et al. used a permeabilization step for the immunocytochemistry but not for the immunohistochemistry to detect
Salmonella ${ }^{29}$ In support of our findings, other studies also used detergents for histologic Salmonella demonstration, although for different applications, e.g., cryosections, thicker sections or immunocytochemistry. ${ }^{30-34}$ The rationale behind the use of detergents in immunocytochemistry and applications using thicker tissue sections or cryosections is to allow the antibody to reach the antigen if it is situated in a cell compartment shielded by a membrane, especially after aldehyde fixation.$^{35}$ Detergents are surface-active molecules that self-associate and bind to hydrophobic surfaces in a concentration-dependent mode. ${ }^{36}$ For example for Saponin, it was demonstrated that through interaction with plasma membrane cholesterol, it makes cells permeable without major

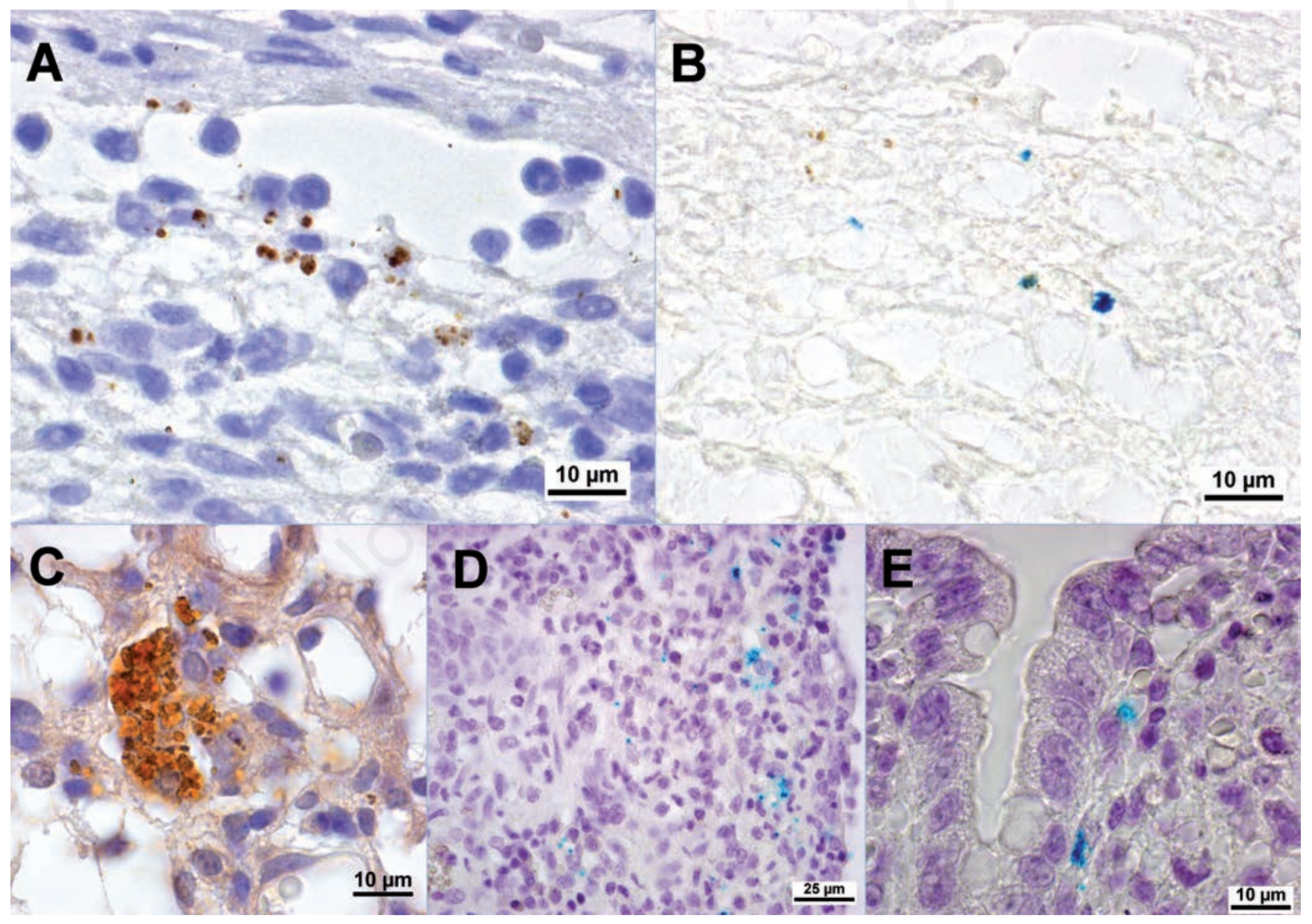

Figure 2. Pigment differentiation. A, B) Subcapsular region of a lymph node. A) Numerous brown staining signals can be observed after staining with protocol 1 but similar ones were also present in IgG as well as buffer control samples $(\rightarrow \mathrm{C})$. B) Neighbouring section next to A. First immunohistochemistry followed by iron demonstration with Berlin blue was carried out on the same slide. Blue reaction product identifying iron and brown staining signal of immunohistochemistry can be distinguished. C) Gold-brown staining signals in the medullary region of a lymph node of a control section. The brown pigments could be observed in such concentrated form and as single objects disseminated throughout the tissue. Please also compare this picture to figure 1C. D, E) Ileal tissue, in which Salmonella was demonstrated with a green-blue (HistoGreen) instead of a brown reaction product. 
disruption of organelles, by literally opening pores in the plasma membrane when used in higher concentrations. ${ }^{37}$ Within mammalian cells, Salmonella inhabits a membrane-bound vacuole known as the Salmonella-containing vacuole but also colonizes the cytosol of cells. ${ }^{38}$ Therefore, we assume that a permeabilization step in the immunohistochemical protocol is necessary to access the bacteria situated in the cytosol as well as the ones in the membrane-surrounded vacuoles. Negative immunohistochemical results may otherwise be false negatives or the amount of detected bacteria artificially low.

To the best of our knowledge, there are very few published detection limits for the immunohistochemical identification of bacte- ria in histological samples $\left(10^{2} \mathrm{CFU} \mathrm{g}^{-1}\right.$ tissue for mycobacteria in fish $^{39}$ ). Based on our observations, we propose a detection limit of roughly $10^{2}-10^{3}$ CFU per g tissue in our experimental setup. The detection limit may of course be different for e.g., different antigens, targeted bacteria and chosen staining protocols, as was also demonstrated in this study. Since some recent studies used enzymes in their staining protocols, this could be another option to enhance sensitivity. ${ }^{40-42} \mathrm{An}$ additional reason for a varying immunohistochemical detection limit may be a potential change of surface structure of $S$. Typhimurium in different environments. The antibody used in this study was directed against heat-inactivated LPS from $S$. Typhimurium. As described in the
Results section, staining signals from $S$ Typhimurium recovered directly out of the culture medium were heterogeneous and mostly weak, whereas those of tissue sections of the ileum and colon were strongly visible. We also noticed differences between the tissue resident bacteria and the ones in the intestinal lumen. The observed size differences between the variably stained bacteria could be attributed to the Quellung reaction.22 Quellung (German word for swelling) is the result of the combination of the polysaccharidal bacterial capsule antigens with the specific antibody, resulting in an apparent capsule swelling. ${ }^{43}$ For the fungus Cryptococcus neoformans, which is used as a system to study capsule reactions because it has a large polysaccha-

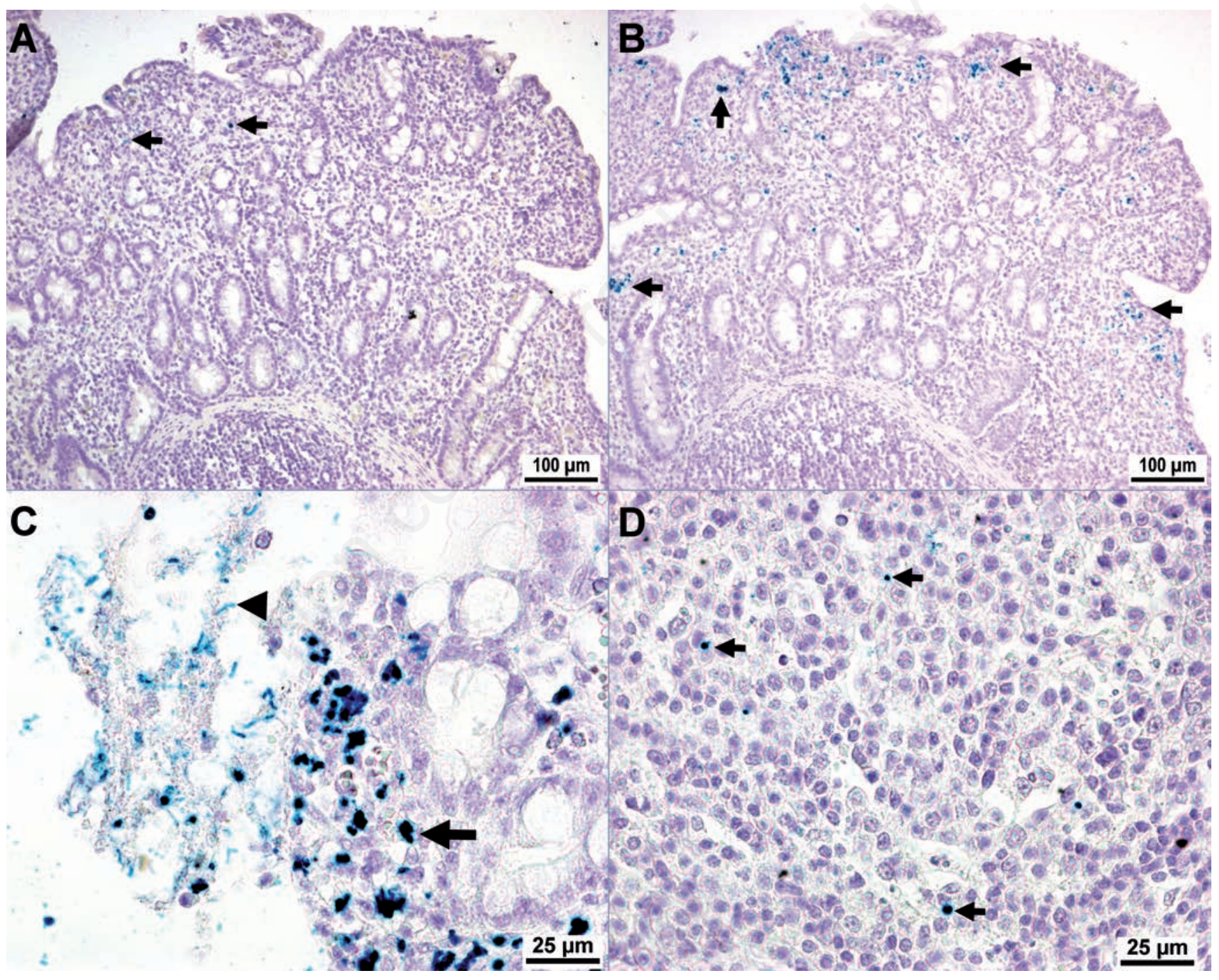

Figure 3. Influence of detergents on the amount of reaction product (Salmonella = green-blue staining signals). A) Ileal mucosa not treated with detergent. Few salmonellae are visible (arrow). B) Serial section next to A. Trition X-100 was used in the staining protocol as a detergent. Numerous salmonellae are visible (arrow). C) Higher magnification of ileal epithelium (B). Salmonellae are also visible in the intestinal lumen. Note the differences in staining intensity of single bacteria inside (arrow) and outside (arrowhead) of the tissue. D) Salmonella (arrow) could also be demonstrated in the tonsils after introducing a detergent in the protocol. Without it, salmonellae were not detectable in this tissue. 
ride capsule that is readily visible by light microscopy, it was shown that distinct capsular reactions depend on the antibody epitope specificity and the yeast serotype. ${ }^{44}$ Therefore different degrees of Quellung-reaction and resulting different detection sensitivities could also be possible in Salmonella-immunohistochemistry. It has been established that phase and antigenic variation lead to substantially altered heterogenic phenotypes of a clonal bacterial population. It has been shown that surface antigens in particular vary under differing conditions, even during the journey through the body, to avoid adverse immune reactions and establish long term persistence. ${ }^{45}$ Another reason for the stronger staining signals detected inside of the intestinal tissues might be the tendency of Salmonella to form microcolonies, ${ }^{46}$ thereby probably amplifying the antigen concentration in one spot. Additionally, the accumulation of dense material surrounding intracellular $S$. Typhimurium, supposedly originating from lysed bacterial products, was described in an transmission electron microscopical study. ${ }^{47}$ This material could also amplify the staining signal.

In conclusion, the use of detergents seems to be necessary for the proper immunohistochemical detection of Salmonella in paraffin embedded tissues and enhances the identification sensitivity. Additionally it is advisable not to use a detection system with brown staining for bacteria in an experimental setup involving intestinal damage including haemorrhage.

\section{References}

1. Hedemann MS, Mikkelsen LL, Naughton PJ, Jensen BB. Effect of feed particle size and feed processing on morphological characteristics in the small and large intestine of pigs and on adhesion of Salmonella enterica serovar Typhimurium DT12 in the ileum in vitro. J Anim Sci 2005;83:1554-62.

2. Kreuzer S, Janczyk P, Aßmus J, Schmidt MFG, Brockmann GA, Nöckler K. Enterococcus faecium NCIMB 10415 shows no beneficiary effects in weaned pigs infected with Salmonella enterica serovar typhimurium DT 104. Appl Environ Microbiol 2012;78:4816-25.

3. Martins RP, Collado-Romero M, MartínezGomáriz M, Carvajal A, Gil C, Lucena C, et al. Proteomic analysis of porcine mesenteric lymph-nodes after Salmonella typhimurium infection. J Proteomics 2012;75:4457-70.

4. Boyen F, Haesebrouck F, Maes D, Van Immerseel F, Ducatelle R, Pasmans F. Non- typhoidal Salmonella infections in pigs: A closer look at epidemiology, pathogenesis and control. Vet Microbiol 2008;130:1-19.

5. Van Parys A, Boyen F, Leyman B, Verbrugghe E, Haesebrouck F, Pasmans F. Tissue-specific Salmonella typhimurium gene expression during persistence in pigs. PLoS ONE 2011;6:e24120.

6. Collado-Romero M, Martins RP, Arce C, Moreno Á, Lucena C, Carvajal A, et al. An in vivo proteomic study of the interaction between Salmonella Typhimurium and porcine ileum mucosa. J Proteomics 2012;75:2015-26.

7. Hulst M, Smits M, Vastenhouw S, Wit A de, Niewold T, Meulen J van der. Transcription networks responsible for early regulation of Salmonella-induced inflammation in the jejunum of pigs. J Inflamm 2013;10:18.

8. Schauser K, Olsen JE, Larsson L-I. Immunocytochemical studies of Salmonella Typhimurium invasion of porcine jejunal epithelial cells. J Med Microbiol 2004;53:691-5.

9. Velge P, Wiedemann A, Rosselin M, Abed $\mathrm{N}$, Boumart Z, Chausse AM, et al. Multiplicity of Salmonella entry mechanisms, a new paradigm for Salmonella pathogenesis. Microbiology Open 2012;1: 243-58.

10. Santos RL, Almeida AP, Xavier MN, Paixão TA, Wilson RP, Dandekar S, et al. Enteric Pathology and Salmonella-Induced Cell Death in Healthy and SIV-Infected Rhesus Macaques. Vet Pathol 2011;48:933-41.

11. Broz P, Ohlson MB, Monack DM. Innate immune response to Salmonella typhimurium, a model enteric pathogen. Gut Microbes 2012;3:62-70.

12. Monack DM. Helicobacter and Salmonella Persistent Infection Strategies. Cold Spring Harb Perspect Med 2013;3:a010348.

13. Ramos-Vara JA, Segalés J, Duran CO, Campbell K, Domingo M. Diagnosing infectious porcine diseases using immunohistochemistry. J Swine Health Prod 1999;7:85-91.

14. Rieger J, Janczyk P, Hünigen H, Neumann $\mathrm{K}$, Plendl J. Intraepithelial lymphocyte numbers and histomorphological parameters in the porcine gut after Enterococcus faecium NCIMB 10415 feeding in a Salmonella Typhimurium challenge. Vet Immunol Immunopathol 2015;164:40-50.

15. Kreuzer S, Rieger J, Strucken EM, Thaben $\mathrm{N}$, Hünigen $\mathrm{H}$, Nöckler $\mathrm{K}$, et al. Characterization of CD4+ subpopulations and CD25+ cells in ileal lymphatic tissue of weaned piglets infected with Salmonella Typhimurium with or without Enterococus faecium feeding. Vet Immunol Immunopathol 2014;158:143-55.

16. Rieger J, Twardziok S, Huenigen $\mathrm{H}$,
Hirschberg RM, Plendl J. Porcine intestinal mast cells. Evaluation of different fixatives for histochemical staining techniques considering tissue shrinkage. Eur J Histochem 2013;57:e21.

17. Mulisch M, Welsch U, editors. [Romeis Mikroskopische Technik].[Book in German], 18th ed. Spektrum Akademischer Verlag; 2010; 556 pp.

18. Romeis B. [Mikroskopische Technik].[Book in German], 16th ed. München, Wien: R. Oldenbourg Verlag; 1968; 757 pp.

19. Thoolen B, Maronpot RR, Harada T, Nyska A, Rousseaux C, Nolte T, et al. Proliferative and nonproliferative lesions of the rat and mouse hepatobiliary system. Toxicol Pathol 2010;38:5S-81S.

20. Costa CAX, de Brito KNO, Gomes MA, Caliari MV. Histopathological and immunohistochemical study of the hepatic lesions experimentally induced by Entamoeba dispar. Eur J Histochem 2010;54:e39.

21. Preziuso S, Sanna E, Sanna MP, Loddo C, Cerri D, Taccini E, et al. Association of Maedi Visna virus with Brucella ovis infection in rams. Eur J Histochem 2009;47: 151-8.

22. McRill CM, Kramer TT, Griffith RW. Application of the peroxidase-antiperoxidase immunoassay to the identification of Salmonellae from pure culture and animal tissue. J Clin Microbiol 1984;20:281-4.

23. Martins RP, Collado-Romero M, Arce C, Lucena C, Carvajal A, Garrido JJ. Exploring the immune response of porcine mesenteric lymph nodes to Salmonella enterica serovar Typhimurium: an analysis of transcriptional changes, morphological alterations and pathogen burden. Comp Immunol Microbiol Infect Dis 2013;36:149-60.

24. Morrison CM, Dial SM, Day WA, Joens LA. Investigations of Salmonella enterica Serovar Newport infections of oysters by using immunohistochemistry and knockout mutagenesis. Appl Environ Microbiol 2012;78:2867-73.

25. Betz P, Eisenmenger W. Morphometrical analysis of hemosiderin deposits in relation to wound age. Int $\mathrm{J}$ Legal Med 1996;108:262-4.

26. Ghadially FN, Walley VM. Pigments of the gastrointestinal tract: a comparison of light microscopic and electron microscopic findings. Ultrastruct Pathol 1995;19:213-9.

27. Szeredi L, Glávits R, Tenk M, Jánosi S. Application of anti-BCG antibody for rapid immunohistochemical detection of bacteria, fungi and protozoa in formalin-fixed paraffin-embedded tissue samples. Acta Vet Hung 2008;56:89-99.

28. Dabbs DJ. Diagnostic immunohistochemistry. Elsevier Health Sciences; 2013; 1157 pp.

29. Searle LEJ, Cooley WA, Jones G, Nunez A, Crudgington B, Weyer U, et al. Purified 
galactooligosaccharide, derived from a mixture produced by the enzymic activity of Bifidobacterium bifidum, reduces Salmonella enterica serovar Typhimurium adhesion and invasion in vitro and in vivo. J Med Microbiol 2010;59:1428-39.

30. Van Parys A, Boyen F, Volf J, Verbrugghe E, Leyman B, Rychlik I, et al. Salmonella Typhimurium resides largely as an extracellular pathogen in porcine tonsils, independently of biofilm-associated genes $\operatorname{csg} A, \operatorname{csg} D$ and adrA. Vet Microbiol 2010;144:93-9.

31. Monaghan P, Watson PR, Cook H, Scott L, Wallis TS, Robertson D. An improved method for preparing thick sections for immuno/histochemistry and confocal microscopy and its use to identify rare events. J Microsc 2001;203:223-6.

32. Loetscher Y, Wieser A, Lengefeld J, Kaiser P, Schubert S, Heikenwalder M, et al. Salmonella Transiently Reside in Luminal Neutrophils in the Inflamed Gut. PLoS ONE 2012;7:e34812.

33. Pilonieta MC, Moreland SM, English CN, Detweiler CS. Salmonella enterica infection stimulates macrophages to hemophagocytose. mBio 2014;5:e2211-14.

34. Brown MD, Bry L, Li Z, Sacks DB. IQGAP1 Regulates Salmonella invasion through interactions with Actin, Rac1, and Cdc42. J
Biol Chem 2007;282:30265-72.

35. Jamur MC, Oliver C. Permeabilization of cell membranes. Methods Mol Biol Clifton NJ 2010;588:63-6.

36. Garavito RM, Ferguson-Miller S. Detergents as tools in membrane biochemistry. J Biol Chem 2001;276:32403-6.

37. Lapetina EG, Watson SP, Cuatrecasas P. myo-Inositol 1,4,5-trisphosphate stimulates protein phosphorylation in saponinpermeabilized human platelets. Proc Natl Acad Sci U S A 1984;81:7431-5.

38. Knodler LA, Nair V, Steele-Mortimer 0. Quantitative Assessment of Cytosolic Salmonella in Epithelial Cells. PLoS ONE 2014;9:e84681.

39. Zerihun MA, Hjortaas MJ, Falk K, Colquhoun DJ. Immunohistochemical and Taqman real-time PCR detection of mycobacterial infections in fish. J Fish Dis 2011;34:235-46.

40. Opriessnig T, Bender JS, Halbur PG. Development and validation of an immunohistochemical method for rapid diagnosis of swine erysipelas in formalinfixed, paraffin-embedded tissue samples. J Vet Diagn Invest 2010;22:86-90.

41. Gonzalez-Escobedo G, Gunn JS. Gallbladder epithelium as a niche for chronic Salmonella carriage. Infect Immun 2013;81:2920-30.
42. Opriessnig T, Madson DM, Roof M, Layton SM, Ramamoorthy S, Meng XJ, et al. Experimental reproduction of porcine circovirus type 2 (PCV2)-associated enteritis in pigs infected with PCV2 alone or concurrently with Lawsonia intracellularis or Salmonella typhimurium. J Comp Pathol 2011;145:261-70.

43. Wikipedia [Internet]. Quellung reaction. Accessed on: 23 Feb 2015. Available from: http://en.wikipedia.org/w/index.php?title= Quellung_reaction\&oldid=571045439

44. MacGill TC, MacGill RS, Casadevall A, Kozel TR. Biological correlates of capsular (Quellung) reactions of Cryptococcus neoformans. J Immunol 2000;164:4835-42.

45. Woude MW van der, Bäumler AJ. Phase and antigenic variation in bacteria. Clin Microbiol Rev 2004;17:581-611.

46. Zhang K, Dupont A, Torow N, Gohde F, Leschner S, Lienenklaus S, et al. Agedependent enterocyte invasion and microcolony formation by Salmonella. PLoS Pathog 2014;10:e1004385.

47. Takeuchi A. Electron microscope studies of experimental Salmonella infection. I. Penetration into the intestinal epithelium by Salmonella typhimurium. Am J Pathol 1967;50:109-36. 